\title{
The Adaptation and Implementation of a Medical-Dental Electronic Health Record in an Academic Dental Center
}

\author{
Maria C. Dolce ${ }^{1}$ Jessica L. Parker ${ }^{2}$ Scott Jason ${ }^{3}$ Catherine R. Ramos ${ }^{4}$ John D. DaSilva ${ }^{5}$
}

${ }^{1}$ School of Nursing, Stony Brook University, Stony Brook, New York, United States

2 School of Nursing, Northeastern University, Boston, Massachusetts, United States

3 Office of Administration and Finance, Harvard School of Dental Medicine, Boston, Massachusetts, United States

${ }^{4}$ Department of Clinical Affairs and Business Development, Harvard School of Dental Medicine, Boston, Massachusetts, United States

${ }^{5}$ Department of Restorative Dentistry and Biomaterials Science, Harvard School of Dental Medicine, Boston, Massachusetts, United States

\author{
Address for correspondence Jessica L. Parker, EdD, RDH, School of \\ Nursing, Northeastern University, 360 Huntington Avenue, 310 \\ Robinson Hall, Boston, MA 02115, United States \\ (e-mail: j.parker@neu.edu).
}

ACI Open 2019;3:e37-e43.

\section{Abstract}

Keywords

- medical-dental

- axiUm

- electronic health record

- electronic dental record
Background Several large health care systems in the United States have pioneered the integration of dentistry into their medical care delivery models. To date, no studies or case reports on combining medical information into the dental electronic health record within U.S. academic dental centers were found in the extant literature.

Objective This report details how we developed and implemented customized primary care elements into axiUm, a popular dental practice management software primarily used in dental schools, to facilitate medical-dental clinical integration. This work was undertaken to provide the infrastructure for nurse practitioners and dentists to deliver a holistic, integrated, person-centered approach to care.

Methods A multidisciplinary design team used the Centers for Disease Control and Prevention's Framework for Patient-centered Health Risk Assessments, an evidence-based framework to guide the adaptation of the existing axiUm dental record. The design featured individual data fields to source data, generate reports, and analyze information to improve clinical care and operations.

Results To date, medical information on more than 260 dental patients over 600 clinic visits has been documented in the adapted electronic health record.

Conclusion The customization capability of axiUm facilitated efficient and effective development and implementation processes. Training and user support were essential for effective implementation and led to further system refinements.

\section{Background and Significance}

Oral health is an integral part of total health and wellness, and achieving optimal oral health and wellness necessitates interprofessional collaboration and coordination among the health care team. ${ }^{1}$ A common electronic health record (EHR) enhances care coordination and facilitates the exchange of clinical information among care providers. ${ }^{2}$ Unfortunately, most medical and dental patient records exist in silos. ${ }^{3}$ Userfriendly access to dental information is critical to delivering a holistic care approach. ${ }^{4}$ Several large health care systems in the United States have pioneered the integration of dentistry received

August 10, 2018 accepted after revision April 9, 2019

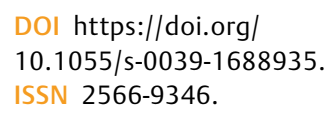

License terms

Stuttgart - New York

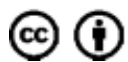


into their care delivery models. ${ }^{5-7}$ To date, no studies or case reports on adapting an electronic dental record (EDR) for primary medical care within U.S. academic dental centers were found in the extant literature.

\section{Objective}

The primary objective of this case report is to describe the development and implementation of customized primary care elements into axiUm, a popular dental practice management software primarily used in dental schools, to facilitate medical-dental clinical integration. Clinical integration refers to the coordination of person-centered, medical and dental care at chairside. This work was undertaken to provide the infrastructure for nurse practitioners (NPs) and dentists to deliver a holistic, person-centered approach to care at chairside, and facilitate effective communication and care coordination.

\section{Case Description}

The Academic Dental Center (ADC) is a state-of-the-art dental care facility located within the School of Dental Medicine and situated in the Longwood medical area of Boston, MA. The ADC utilizes axiUm (Exan Group, Henry Schein, Melville, New York, United States) EDR, a Health Insurance Portability and Accountability-compliant, certified system that includes billing and practice management applications. The axiUm platform was designed to address the needs of educational institutions and over $90 \%$ of North American dental schools use axiUm. ${ }^{8}$

\section{Methods}

A multidisciplinary design team was guided by three underlying principles. (1) Medical care components of the EHR are aligned with an evidence-based patient-centered framework for health promotion and disease prevention. (2) Medical health information is centralized for convenient, userfriendly access by all health care providers. (3) Data entry, clinical decision support, and medical coding/billing are priority areas for medical-dental clinical integration. The design team consulted with end-users to test the workflow and design of the changes.

\section{Development Process}

The Centers for Disease Control and Prevention's Framework for Patient-centered Health Risk Assessments ${ }^{9}$ informed the development process. Medical components of the EHR were derived from the Medicare Annual Wellness Visit (AWV). ${ }^{10}$ Key components and elements of the AWV are listed in -Table 1. Other important components were included such as patient referrals, appointments, treatment planning, provider alerts, problems lists, educational resources, progress notes, and medications.

Configuring a centralized location for medical information so that patient health information could be accessed quickly by all providers was a priority. An ideal location for the addition of medical information was identified within the forms tab of the EHR ( $\sim$ Fig. 1). New medical templates were created and embedded within this central location, including health risk assessment (-Fig. 2), depression screening, and fall risk assessment. A group of end-users tested the workflow of the new templates and recommended changes.

A new security level was created in axiUm for the NP. Security levels are also configured so that users have access to only the information they need to perform the duties of their job. Data fields were programmed to generate alerts for providers, and data entry was configured into individual fields to facilitate data mining and reporting. For example, alerts were created to notify dental providers that their patient was past due for a primary care visit, and NP providers about due dates for dental cleaning and/or periodic oral examination. A free-text form was created for the documentation of progress notes. Specific clinical data fields (e.g., blood pressure, pulse, height, and weight) were duplicated in the nursing and dental history and assessment forms to ensure that dental student providers were developing competency in obtaining vital signs and pertinent health information.

A medication inventory list was created so that all providers could access patient's current medication list and view changes. The ADC uses DrFirst (https://www.drfirst.com), an e-prescribing solution that gives providers access to all medications that the patient has been prescribed in the United States, and a common method of connecting and communicating via a fast, secure, and reliable network. DrFirst automates new prescriptions and refill requests/ responses and improves the overall efficiency of the prescription process. UpToDate, an evidence-based, electronic clinical decision support resource, was made available to the NP. Patient education materials and resources on common health topics, such as asthma, blood pressure, and smoking cessation, were added to the EHR.

Current Procedural Terminology (CPT) and International Statistical Classification of Diseases (ICD-10) diagnostic codes were configured into axiUm. The CPT codes activated for services rendered by the NP could be linked to ICD-10 codes for medical billing. A super bill or charge slip/ticket template ( $>$ Fig. 3) was created to capture the medical services offered and served as a prompt for NP providers to document billable services. Codes were derived from the American Medical Association's evaluation and management guidelines ${ }^{11}$ and ICD-10CM diagnostic and procedures codes. ${ }^{12}$ Bundled codes were created based on the components of the AWV.

\section{Implementation Process}

Prior to implementation, usability and error testing were conducted to evaluate users' ease of documentation, form behavior, data mining, and reporting. After the system was designed and implemented in the axiUm test system, the new forms were presented to the design team. The design team tested workflows for errors and suggested enhancements to improve usability. The clinical applications director 
Table 1 Components of the Annual Wellness Visit

\begin{tabular}{|c|c|}
\hline Component & Specific elements \\
\hline Health risk assessment & $\begin{array}{l}\text { Collect the following information: } \\
\text { - Demographic data } \\
\text { - Self-assessment of health status } \\
\text { - Psychosocial risks } \\
\text { - Behavioral risks } \\
\text { - Activities of daily living (ADLs), including but not limited to: dressing, bathing, and walking } \\
\text { - Instrumental ADLs, including but not limited to: shopping: housekeeping, managing own } \\
\text { medications, and handling finances }\end{array}$ \\
\hline $\begin{array}{l}\text { List of current providers } \\
\text { and suppliers }\end{array}$ & Obtain a list of current providers and suppliers that regularly provide medical care to the patient \\
\hline Medical/family history & $\begin{array}{l}\text { Collect information about: } \\
\text { - Past medical/surgical history } \\
\text { - Current medications and supplements } \\
\text { - Family history } \\
\text { - History of alcohol, tobacco, and illicit drug use } \\
\text { - Diet } \\
\text { - Physical activities }\end{array}$ \\
\hline $\begin{array}{l}\text { Review risk factors for } \\
\text { depression and } \\
\text { other mood disorders }\end{array}$ & $\begin{array}{l}\text { Obtain current or past experiences with depression and use any appropriate screening } \\
\text { instrument for patients without a current diagnosis of depression }\end{array}$ \\
\hline $\begin{array}{l}\text { Review functional ability } \\
\text { and level of safety }\end{array}$ & $\begin{array}{l}\text { Use appropriate screening questions to address the following areas: } \\
\text { - ADLs } \\
\text { - Fall risk } \\
\text { - Hearing impairment } \\
\text { - Home safety }\end{array}$ \\
\hline End-of-life planning & $\begin{array}{l}\text { Provide verbal or written information about the patient's ability to prepare } \\
\text { an advanced directive }\end{array}$ \\
\hline Exam & $\begin{array}{l}\text { - Height } \\
\text { - Weight } \\
\text { - Body mass index (BMI) } \\
\text { - Blood pressure } \\
\text { - Visual acuity screening } \\
\text { - Any other relevant factors }\end{array}$ \\
\hline $\begin{array}{l}\text { Educate, counsel, } \\
\text { and refer for other } \\
\text { preventive services }\end{array}$ & Include a written plan, such as a checklist, for the patient \\
\hline
\end{tabular}

Source: Adapted from The ABCs of the Annual Wellness Visit, Medical Learning Network, 2014.

worked with axiUm developers to migrate all final documentation pathways and forms into the production system.

Providers received training through didactic sessions with hands-on demonstration. During the implementation period, we incorporated user feedback to fine-tune the system. Modifications were tested for improvement using plan-dostudy-act (PDSA) cycles and reviewing customized data reports. To ensure ongoing quality improvement, custom reports were developed to query data on clinical outcomes. Results were analyzed monthly, shared with providers, and reported quarterly to the ADC Quality Committee.

\section{Discussion}

Customized primary care EHR templates were successfully implemented to facilitate medical-dental clinical integration. To date, medical information on more than 260 dental patients over 600 clinic visits has been documented in the EHR. The outcome was a replicable electronic infrastructure to support the clinical integration of primary care medical services in an academic dental center. We recognize that the outcome is not an integrated EHR, and agree that to fully support person-centered care, we need robust, integrated and interoperable EHRs to move into the dental care arena. ${ }^{13}$

To the best of our knowledge, this is the first dental education program to configure the axiUm platform for medical-dental clinical integration. The integration of oral health and medical/wellness services within U.S. academic dental clinics is gaining momentum, ${ }^{14-17}$ particularly in the context of advancing interprofessional education, personcentered care, and collaborative practice competencies. ${ }^{18}$ Since axiUm is widely used in most dental schools, this report contributes to advancing these efforts in U.S. dental education by providing academic dental schools with a feasible and affordable solution.

Several key factors contributed to a successful implementation. We found that a multidisciplinary team approach was a primary success characteristic. A high-performing 


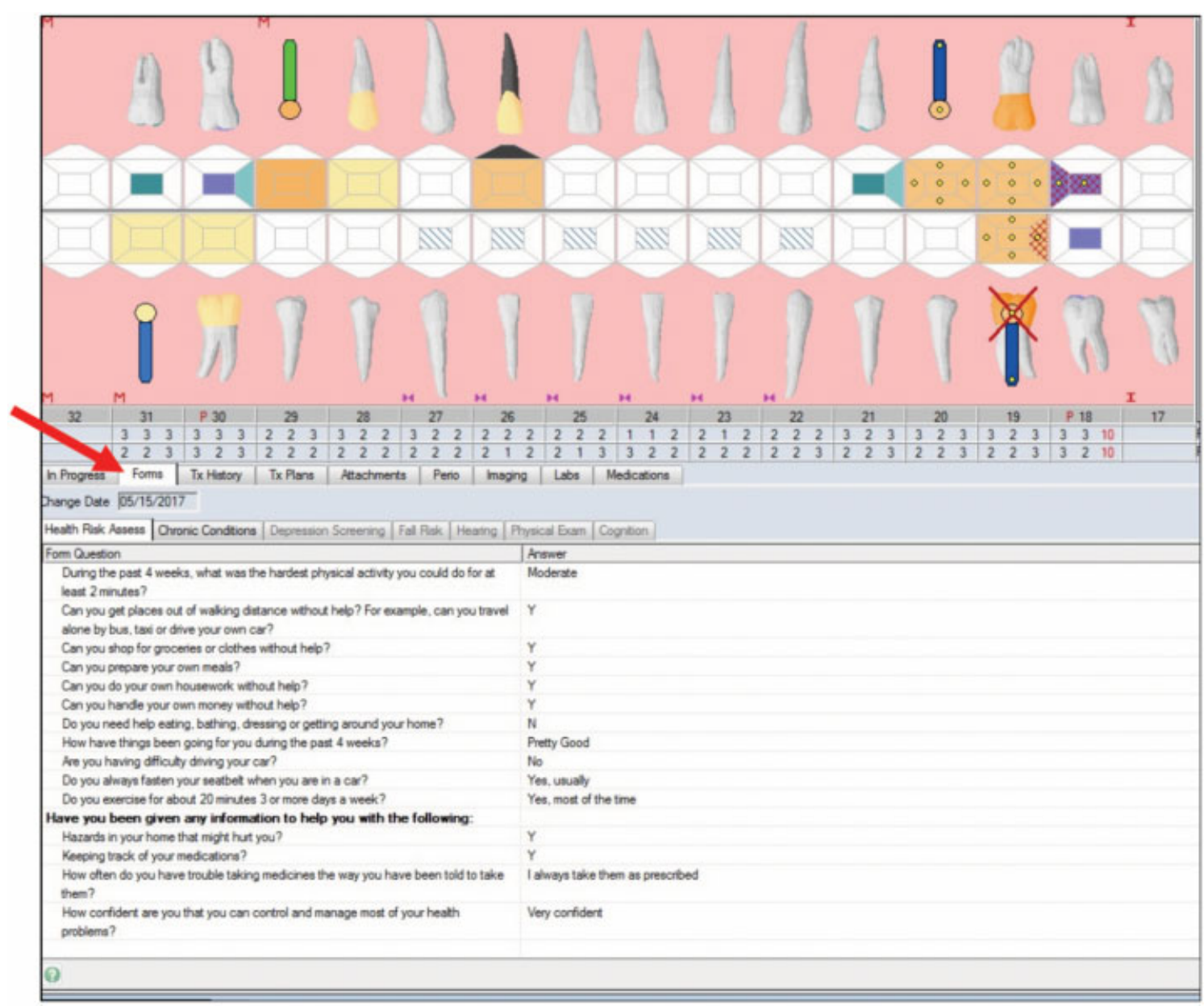

Fig. 1 The existing forms tab was identified as the location for the addition of medical information.

multidisciplinary team is characterized by collaboration, recognition of individual roles, and contributions to a shared purpose. ${ }^{19}$ It was important to have professional, managerial, administrative, and front-line support staff on the team. Our initial step was to establish consensus and ensure commitment ${ }^{20}$ around our strategic goal-to improve oralsystemic health for older adults living with chronic health conditions. The team agreed on the need for incorporating primary medical information into the EDR to support our integrated, person-centered care model. We reviewed existing workflow processes and mapped new process flowcharts to support the innovative care delivery model. High-level leadership and organizational support was critical. ${ }^{20}$ Our team reported to a strategic advisory group comprised of nursing and dental school deans and directors. The leadership remained steadfast in supporting our purpose, providing resources to achieve our goals, and empowering team autonomy with accountability. ${ }^{19}$ The impact of executive leadership support was immeasurable in terms of professional stakeholder buy-in, particularly with community primary care providers. Engaging primary care providers and specialists in the community was important to facilitate referrals and coordinate comprehensive care. An important phase of the project was usability testing. We first conducted a usability heuristic evaluation with a small group of eva- luators. Heuristic evaluation is a systematic examination to identify usability problems in the user interface design so that they can be addressed in an iterative design process. ${ }^{21}$ Next, we conducted end-user testing with NPs and dental providers in the dental center which led to further system refinements. This step provided valuable information about the use of and problems with the templates. Training and end-user support were vital for effective implementation. Initial training was tailored for the individual roles of NPs and dentist providers. ${ }^{20}$ Interprofessional training was conducted in the dental center work environment and included hands-on practice. We recognized the need for continuous training as new students enter their respective programs yearly. It was essential to continuously monitor and evaluate EHR refinements and changes in workflow processes. Our priority was to acquire user feedback and respond to problems timely. ${ }^{20}$ We followed a model for improvement for testing ideas using PDSA cycles to rapidly reach our goals. ${ }^{19}$

Notable implementation challenges included axiUm's lack of interoperability and medical decision support functionalities. The existing axiUm system at ADC does not have the interoperability to exchange patients' health care information with outside medical providers and specialists. Therefore, the NP requested copies of patients' medical records and exchanges pertinent health information 


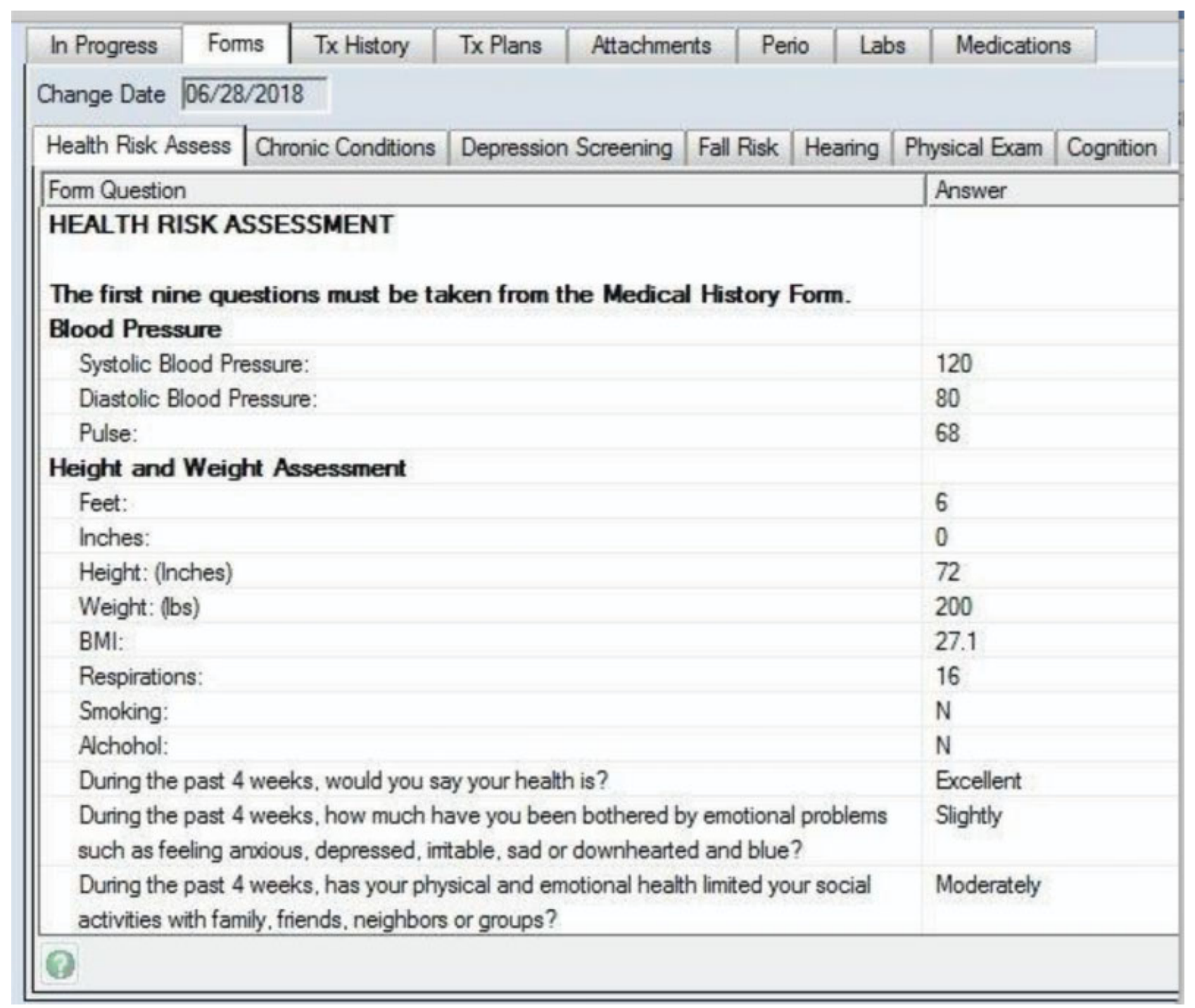

Fig. 2 Health risk assessment template.

directly over the phone or using facsimile transmission. In addition, the existing axiUm system was not programmed with medical decision support functionality. To address this challenge, access to UpToDate, an evidence-based, electronic clinical decision support resource, was made available to the NP.

A major lesson learned was the need to budget sufficient time to plan with end-users and collaborate with axiUm developers. We learned that axiUm developers or an experienced Crystal Reports writer was needed to develop custom forms. We recommend that dental schools start working with axiUm developers on the first day of planning so that the design team has the opportunity to understand the limitations and customizability options of the software.

The customization capability of axiUm facilitated efficient and effective development and implementation processes. This capability allowed the school's axiUm administrator to modify the software application without permission from the developer. Our decision to design individual data fields allowed us to source data, generate reports, and analyze information to improve clinical care and operations. Inter- professional communication was facilitated by the existing internal messaging feature, axiUm messenger, which enabled NPs and dental providers to communicate and exchange patient information timely, accurately, and effectively. The medical-dental EHR is available to all health care providers in the ADC. Our next step is to test the medical coding/billing infrastructure for medical claims submission and payer reimbursement.

\section{Clinical Relevance Statement}

The successful adaptation of axiUm to include primary care templates presents an opportunity for other academic dental centers to replicate and customize the dental EHR to facilitate similar medical-dental clinical integration. Dental patients will benefit from clinical integration through improved care coordination and communication between medical and dental providers. Dental students and other health care professional students will be prepared with competencies for clinical integration, including interprofessional collaboration, communication, care coordination, and clinical informatics skills. 


\begin{tabular}{|c|c|c|c|}
\hline \multirow[t]{2}{*}{ CODE } & & \multicolumn{2}{|l|}{ CODE } \\
\hline & OFFICE VISITS - NEW PATIENTS & & ICD 10 DIAGNOSES CODE \\
\hline 99201 & LEVEL 1. BRIEF: $10 \mathrm{~min}$ & E11.9 & Type 2 diabetes mellitus without complications \\
\hline 99202 & LEVEL 2. LIMITED: $20 \mathrm{~min}$ & 110 & Essential (primary) hypertension \\
\hline 99203 & LEVEL 3. EXPANDED: $30 \mathrm{~min}$ & E66.3 & Overweight \\
\hline 99204 & LEVEL 4. COMPREHENSIVE: $45 \mathrm{~min}$ & E66.9 & Obesity, unspecified \\
\hline \multirow[t]{2}{*}{99205} & LEVEL 5. COMPREHENSIVE: $60 \mathrm{~min}$ & F32.9 & Major depressive disorder, single episode, unspecified \\
\hline & PREVENTIVE EXAM - NEW PATIENTS & $\mathrm{F} 41.8$ & Other specified anxiety disorders \\
\hline G0438 & MEDICARE, Annual Wellness Visit, Initial & \multirow[t]{2}{*}{$\overline{Z 00.00}$} & Encounter for general adult medical exam w/o abnormal \\
\hline G0439 & MEDICARE, Annual Wellness Visit, Subsequent & & findings \\
\hline \multirow[t]{2}{*}{99387} & PREVENTIVE MEDICINE, 65+ & Z00.01 & Encounter for general adult medical exam w/abnormal findings \\
\hline & OFFICE VISITS - EST. PATIENTS & R03.0 & Elevated blood pressure reading w/o Dx of HTN \\
\hline 99211 & LEVEL 1. BRIEF: 5 min & Z00.01 & Encounter for general adult medical exam w/abnormal findings \\
\hline 99212 & LEVEL 2. LIMITED: $10 \mathrm{~min}$ & M13.80 & Other specified arthritis, unspecified site \\
\hline 99213 & LEVEL 3. EXPANDED: $15 \mathrm{~min}$ & Z01.30 & Encounter for exam of blood pressure w/o abnormal findings \\
\hline 99214 & LEVEL 4. COMPREHENSIVE: $25 \mathrm{~min}$ & Z01.31 & Encounter for exam of blood pressure w/abnormal findings \\
\hline 99215 & PREVENTIVE EXAM - EST. PATIENTS & R63.4 & Abnormal weight loss \\
\hline \multirow[t]{2}{*}{99397} & PREVENTIVE MEDICINE, $65+$ & R63.5 & Abnormal weight gain \\
\hline & COUNSELING & Z63.79 & Other stressful life events affecting family and household \\
\hline 99401 & PREVENTIVE COUNSELING: 15 MIN & R53.82 & Chronic fatigue, unspecified \\
\hline 99402 & PREVENTIVE COUNSELING: $30 \mathrm{MIN}$ & R86.19 & Personal history of other infectious/parasitic disease \\
\hline 99403 & PREVENTIVE COUNSELING: 45 MIN & Z86.73 & Personal history of transient ischemic attack (TIA) \\
\hline \multirow[t]{2}{*}{99406} & MEDICARE, smoking and tobacco-use cessation & Z91.81 & History of falling \\
\hline & counseling visit, intermediate & $\overline{Z 95.1}$ & Presence of aortocoronary bypass graft \\
\hline
\end{tabular}

Fig. 3 Sample superbill.

Protection of Human and Animal Subjects

No human/animal subjects were involved in the project.

Funding

This study was funded by HRSA (grant/award number: UD7HP28534) and the U.S. Department of Health and Human Resources, Health Resources and Services Administration, through the Nurse Education, Practice, Quality, and Retention Program for Interprofessional Collaborative Practice.

\section{Conflict of Interest}

None declared.

\section{Acknowledgments}

The authors would like to gratefully acknowledge Dr. Bruce R. Donoff, Dean, Harvard School of Dental Medicine and Dr. Nancy Hanrahan, Dean and Professor, School of Nursing, Northeastern University for their continued leadership and involvement in the Nurse Practitioner-Dentist Program.

\section{References}

1 U.S. Department of Health and Human Services. Oral health in America: a report of the Surgeon General 2000. Rockville, MD: Office of the Surgeon General May 2000. Available at: https:// profiles.nlm.nih.gov/ps/retrieve/ResourceMetadata/NNBBJT/. Accessed July 3, 2018

2 Burton LC, Anderson GF, Kues IW. Using electronic health records to help coordinate care. Milbank Q 2004;82(03):457-481

3 Rudman W, Hart-Hester S, Jones W, Caputo N, Madison M. Integrating medical and dental records. A new frontier in health information management. J AHIMA 2010;81(10):36-39

4 Acharya A, Shimpi N, Mahnke A, Mathias R, Ye Z. Medical care providers' perspectives on dental information needs in electronic health records. J Am Dent Assoc 2017;148(05):328-337
5 Snyder JJ. Permanente Dental Associates P.C.: integrated care case study. J Calif Dent Assoc 2016;44(03):173-175

6 Acharya A. Marshfield Clinic Health System: integrated care case study. J Calif Dent Assoc 2016;44(03):177-181

7 Gesko DS. HealthPartners: integrated care case study. J Calif Dent Assoc 2016;44(03):186-189

8 Exan. See what our customers are saying 2018. Available at: https://www.exansoftware.com/axium/. Accessed July 3, 2018

9 Goetzel RZ, Staley P, Ogden L, Stange P, Fox J, Tabrizi M, et al. A framework for patient-centered health risk assessments: providing health promotion and disease prevention services to medicare beneficiaries 2011. Atlanta, GAUS Department of Health and Human Services, Centers for Disease Control and Prevention2011. Available at: https://www.cdc.gov/policy/hst/hra/frameworkforhra.pdf. Accessed August 2, 2014

10 Centers for Medicare \& Medicaid Services, Medicare Learning Network. The ABCs of the Annual Wellness Visit [updated 2017] Available at: https://www.cms.gov/Outreach-and-Education/Medicare-Learning-Network-MLN/MLNProducts/downloads/awv_chart _icn905706.pdf. Accessed August 3, 2014

11 Centers for Medicare and Medicaid Services. Evaluation and management services 2017. Available at: https://www.cms.gov/Outreach-and-Education/Medicare-Learning-Network-MLN/MLNProducts/Downloads/eval-mgmt-serv-guide-ICN006764.pdf. Accessed February 2, 2015

12 Centers for Medicare and Medicaid Services and National Center for Health Statistics. International Classification of Diseases, 10th Revision, Clinical Modification 2010. Available at: https://www. cdc.gov/nchs/icd/icd10cm.htm. Accessed July, 32018

13 Payne TH, Corley S, Cullen TA, et al. Report of the AMIA EHR-2020 Task Force on the status and future direction of EHRs. J Am Med Inform Assoc 2015;22(05):1102-1110

14 Haber J, Spielman AI, Wolff M, Shelley D. Interprofessional education between dentistry and nursing: the NYU experience. J Calif Dent Assoc 2014;42(01):44-51

15 Ismail AI. Our brand is transforming oral health. Maurice $\mathrm{H}$. Kornberg School of Dentistry Magazine 2016. Available at: https:// dentistry.temple.edu/sites/dentistry/files/uploads/Diamond_Winter2016.pdf. Accessed June 29, 2018 
16 Morgan C. Indiana University nursing and dental students learn clinical skills together in new experiential program. Daily Nurse. [online] 2018. Available at: https://dailynurse.com/ indiana-university-nursing-and-dental-students-learn-clinicalskills-together-in-new-experiential-program/. Accessed June 23, 2018

17 University of Louisville School of Dentistry News. New clinic gives dental patients immediate access to nurse practitioner managed care 2018. Available at: http://louisville.edu/dentistry/news/ new-clinic-gives-dental-patients-immediate-access-to-nurse-practitioner-managed-care. Accessed June 29, 2018
18 Dolce MC, Parker JL, Werlein D. Interprofessional education and practice in oral health: an implementation guide. J Interprof Care 2017;31(01):1-4

19 Nelson EC, Batalden PB, Godfrey MM. Quality by Design: A Clinical Microsystems Approach. San Francisco, CA: Jossey-Bass (OLD 22); 2007

20 Cresswell KM, Bates DW, Sheikh A. Ten key considerations for the successful implementation and adoption of large-scale health information technology. J Am Med Inform Assoc 2013;20(e1):e9-e13

21 Nielsen J. Usability Engineering. San Francisco, CA: Morgan Kaufmann Publishers; 1993 